\title{
Investigation of Fatigue and Compression Strength for the PMMA Reinforced by Different System for Denture Applications
}

\author{
Sihama Issa Salih, Jawad Kadhum Oleiwi, Qahtan Adnan Hamad \\ Materials Engineering Department, University of Technology, Baghdad, Iraq \\ Email address: \\ sihama_salih@yahoo.com (S. I. Salih), jawadkad@yahoo.com (J. K. Oleiwi), qah84@yahoo.com (Q. A. Hamad) \\ To cite this article: \\ Sihama Issa Salih, Jawad Kadhum Oleiwi, Qahtan Adnan Hamad. Investigation of Fatigue and Compression Strength for the PMMA \\ Reinforced by Different System for Denture Applications. International Journal of Biomedical Materials Research. \\ Vol. 3, No. 1, 2015, pp. 5-13. doi: 10.11648/j.ijbmr.20150301.13
}

\begin{abstract}
In the present search, attempts are made to develop the properties of PMMA resin that used for upper and lower prosthesis complete denture, by addition two different types of particles, which included: nano-hydroxyapatite (nHA) particles and micro-zirconia $\left(\mathrm{ZrO}_{2}\right)$ particles that added with different volume fractions of $(1 \%, 2 \%$ and $3 \%)$ to poly methyl methacrylate (PMMA) cold cured resin as new fluid resin as a matrix. Also woven glass fiber kind (E-glass) and woven Kevlar fiber kind (49), it were added with a fixed volume fraction of $(5 \%)$ to PMMA composites. In this work the composite prosthetic dentures specimens preparation was done by using (Hand Lay-Up) method as six groups which includes: the first group consists of

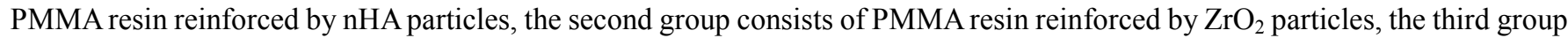
consists of (PMMA-nHA) and glass fiber layer as laminated composite, the fourth group consists of $\left(\mathrm{PMMA}^{-\mathrm{ZrO}} \mathrm{P}_{2}\right)$ and glass fiber layer, the fifth group consists of (PMMA-nHA) and Kevlar fiber layer and the sixth group consists of $\left(\mathrm{PMMA}^{\mathrm{Z}} \mathrm{ZrO}{ }_{2}\right)$ and Kevlar fiber layer. The compression test result shows that the values of compression strength increased with increasing the volume fraction of ( $\mathrm{nHA}$ and $\left.\mathrm{ZrO}_{2}\right)$ particles for all groups' specimens. And the results showed the $\left(\mathrm{PMMA}^{-} \mathrm{ZrO} \mathrm{C}_{2}\right)$ composite has greater values for compression strength. As well as the results shows that the maximum value of compression strength for hybrid laminated composite is obtained in hybrid laminated composite materials for fourth groups' specimens $\left(\mathrm{PMMA}^{-\mathrm{ZrO}} \mathrm{C}_{2}-5 \% \mathrm{Glass}\right.$ Fiber). Whereas the values of fatigue strength of hybrid laminated composite (PMMA-5\% Kevlar fiber-3\% nHA), it was higher than the fatigue strength of hybrid laminated composite (PMMA-5\% Glass fiber-3\% nHA) and the base material (Pure PMMA). The fatigue strength values at $\left(10^{6}\right)$ loading Cycle for these specimens were $(52,38$ and $15 \mathrm{MPa})$ respectively.
\end{abstract}

Keywords: Composite Materials, PMMA, H.A Particles, $\mathrm{ZrO}_{2}$ Particles, Glass Fibers, Kevlar Fibers, Fatigue Strength, Compression Strength

\section{Introduction}

The industrial technological developments gave up rise to an ever increasing demand of some industrial materials with selected mechanical and chemical properties. Thus, new materials with special properties are in continuous need and as result in new field of composite materials started to develop specially in the last twenty years [1].

The composite materials have many important mechanical properties which make them suitable for many industrial uses. This is approach the scientist to researching the effected of different type of reinforced phase on the mechanical properties for the composite material, such as (fatigue strength, compression strength, etc) some researches which are accomplished in this field it's:-

Schajpal and Sood, added silver powder, copper and aluminum $99.9 \%$ pure with average particle size of $10 \mu \mathrm{m}$ into PMMA acrylic denture base resin in ratio of $(5 \%, 10 \%$, $15 \%, 20 \%$ and $25 \%$ ) by volume fraction. It was found that all of the metal fillers marginally increased compressive strength, but a decrease in tensile strength resulted as the percentage of filler was increased, silver and copper made the resin more radio - opaque, while aluminum did not, the fillers increased thermal conductivity progressively but did not proportionally as the filler concentration increased [2].

Wiskott and Belser evaluated the compressive and tensile 
stresses on the cement interface with tooth and crown. Their result shows that there is great compatibility with hypothesis that resistance to lateral displacement is a function of the compressive activity distribution on the cement interface [3].

Fuji researching the fatigue properties of heat and chemically cured acrylic denture base materials. It was found that the fatigue limit of heat cured acrylic was higher than that of the chemically cured acrylic. In addition, pointed out that the fatigue limit was improved by the addition of cross linking agent, and it was found that the elastic modulus, toughness and tensile strength were reduced for samples that had been subjected to fatigue [4].

Vallittu. P. K. et. al. researching the fatigue resistance of heat- polymerized acrylic resin, test specimens reinforced with continuous glass fibers or metal wire was investigated. The specimens were tested by a constant force, flexural fatigue test at a force of $(180 \mathrm{~N})$ while immersed in water at $\left(37^{\circ} \mathrm{C}\right)$. Results showed that the test specimens, which were either unreinforced or reinforced with metal wires, fractured after (13197 to 39237) loading cycles respectively. For the glass fiber- reinforced test specimens, the fracture did not coincide with the region of the strengthener but with the opposite side the test specimens after (1239298) loading cycles [5].

The complete dentures are realizing by Cristina Bortun et. al. from different acrylic resins and various technologies. The durability of complete dentures was estimated by finite element analysis, static tensile tests and fatigue tests. The calculation was finally validated by a fatigue experimental test. The results of the static tensile tests for super acryl plus shows that the ultimate tensile strength $(66.32 \mathrm{MPa})$; young's modulus (5333 MPa); total elongation at fracture $(11.96 \%)$. The fatigue strength was $(11.904 \mathrm{MPa})$. The results showed a good fatigue resistance of material super acryl. The fatigue resistance for super acryl plus is (12 MPa) [6].

The aim of this research is researching the effect of selected volume fractions of nano-hydroxyapatite (nHA) particles, micro-zirconia $\left(\mathrm{ZrO}_{2}\right)$ particles and woven glass fiber and woven Kevlar fiber on the fatigue strength and compression strength of the composite prosthetic denture.

\section{Materials and Methods}

\subsection{Materials Used}

In this research the composite prosthetic dentures specimens consist of polymer matrix and reinforced materials (relatively high stiffness and high wear resistance).

Matrix Material included PMMA cold curing that used in this research as new pour (fluid) resin matrix, type (Castavaria) made from (Vertex - Dental Company), to preparation specimen as hybrid and non hybrid laminated composites of the denture prosthetic. Vertex ${ }^{\mathrm{TM}}$ Castavaria is a multifunctional self polymerizing acrylic which is perfectly useable as a pouring, relining, rebasing and as a repair acrylic.

This type of materials distinguishes by many properties compared with other type of PMMA polymer such as: softer feel, low molecular weight, color stable in the long run, minimized shrinkage, stable polymerization cycle with a perfect end result, the acrylic is long pourable and modelable for a long period of time. But have low strength, low hardness and more difficult using during fabrication [7].

Two types of particles were used as reinforces materials with volume fraction of $(1 \%, 2 \%$ and $3 \%)$ it was added to the polymer powder (acrylic powder) including: the zirconium oxide $\left(\mathrm{ZrO}_{2}\right)$ is supplied as partially stabilized particles form, which made from (ZIRCONIA SALES-GUI 185 SS-U.K Company). The average diameter was $(112.31 \mathrm{~nm})$ is obtained by using atomic force microscopy (AFM). The result of particle size distribution is shown in Figure (1). Table (1) shows the mechanical and physical properties of $\left(\mathrm{ZrO}_{2}\right)$ particle. And hydroxyapatite (HA) is supplied as a nano-particles form, and represented as chemical formula $\mathrm{Ca}_{5}$ $\left(\mathrm{Po}_{4}\right)_{3} \mathrm{OH}$, which made from (Merck, Darmstadt, Germany Company), the average diameter was $(69.97 \mathrm{~nm})$, is obtained by using AFM. The result of particle size distribution of (HA) particles is shown in Figure (2). Table (2) shows the mechanical and physical properties of (HA) particle.

Two types of fibers were used including: E-glass fiber made from (Mowding LTD-U.K Company), as form a woven mat with fibers angle direction $\left(0 \circ / 90^{\circ}\right)$ and volume fraction $(5 \%)$.

The Kevlar 49 fiber made from (E.I.Dupont de. Nomours Company), as form a woven mat with fibers angle direction $(0 \circ / 90 \circ)$ and volume fraction $(5 \%)$.

Table (1). Some Mechanical and Physical Properties of $\mathrm{ZrO}_{2}$ Particles used in this Study according to (ZIRCONIA SALES-GUI 185 SS-U.K Company).

\begin{tabular}{lllllll}
\hline Type of Particle & Tensile Strength (MPa) & Young's Modulus (GPa) & Possion's Ratio & $\begin{array}{l}\text { Compression } \\
\text { Strength (MPa) }\end{array}$ & $\begin{array}{l}\text { Flexural } \\
\text { Strength (MPa) }\end{array}$ & $\begin{array}{l}\text { Density } \\
\left(\mathbf{g m} / \mathbf{c m}^{\mathbf{3}}\right)\end{array}$ \\
\hline Zirconium Oxide & $800-1500$ & $205-210$ & $0.23-0.31$ & 2000 & $900-1200$ & $5.7-6.1$ \\
\hline
\end{tabular}

Table (2). Some Mechanical and Physical Properties of H.A Particles used in this Study according to (Merck, Darmstadt, Germany Company).

\begin{tabular}{|c|c|c|c|c|c|c|}
\hline Type of Particle & Tensile Strength (MPa) & $\begin{array}{l}\text { Young's } \\
\text { Modulus (GPa) }\end{array}$ & Possion's Ratio & $\begin{array}{l}\text { Compression } \\
\text { Strength (MPa) }\end{array}$ & $\begin{array}{l}\text { Flexural Strength } \\
\text { (MPa) }\end{array}$ & $\begin{array}{l}\text { Density } \\
\left(\mathrm{gm} / \mathrm{cm}^{3}\right)\end{array}$ \\
\hline Hydroxyapatite & $40-100$ & $70-120$ & 0.28 & $100-900$ & $20-80$ & $3.08-3.18$ \\
\hline
\end{tabular}




\begin{tabular}{|c|c|c|c|c|c|c|c|c|}
\hline \multicolumn{9}{|c|}{ Granularity Cumulation Distribution Report } \\
\hline \multicolumn{4}{|c|}{ Sample: $\mathrm{ZRO}_{2}$} & \multicolumn{5}{|c|}{ Code: Sample Code } \\
\hline \multicolumn{4}{|c|}{ Line No.: lineno } & \multicolumn{5}{|c|}{ Grain No.: 105} \\
\hline \multicolumn{4}{|c|}{ Instrument: CSPM } & \multicolumn{4}{|c|}{ Date: $2013-02-09$} & \\
\hline \multicolumn{9}{|c|}{ Avg. Diameter: $112.31 \mathrm{~nm}$} \\
\hline $\begin{array}{c}\text { Diameter } \\
\mathrm{nm})<\end{array}$ & $\begin{array}{c}\text { Volume } \\
(\%)\end{array}$ & $\underset{\mathrm{n}(\%)}{\text { Cumulatio }}$ & $\begin{array}{c}\text { Diameter }( \\
\mathrm{nm})<\end{array}$ & $\begin{array}{c}\text { Volume } \\
(\%)\end{array}$ & $\begin{array}{c}\text { Cumulatio } \\
\mathrm{n}(\%)\end{array}$ & 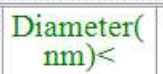 & $\begin{array}{c}\text { Volume } \\
(\%)\end{array}$ & $\begin{array}{c}\text { Cumulatio } \\
\mathrm{n}(\%)\end{array}$ \\
\hline $\begin{array}{c}70.00 \\
80.00 \\
90.00 \\
100.00 \\
110.00\end{array}$ & \begin{tabular}{c|}
9.52 \\
12.38 \\
13.33 \\
10.48 \\
7.62
\end{tabular} & $\begin{array}{c}9.52 \\
21.90 \\
35.24 \\
45.71 \\
53.33\end{array}$ & $\begin{array}{l}120.00 \\
130.00 \\
140.00 \\
150.00 \\
160.00\end{array}$ & $\begin{array}{c}12.38 \\
10.48 \\
5.71 \\
0.95 \\
3.81\end{array}$ & $\begin{array}{l}65.71 \\
76.19 \\
81.90 \\
82.86 \\
86.67\end{array}$ & $\begin{array}{l}170.00 \\
180.00 \\
200.00 \\
210.00 \\
220.00\end{array}$ & $\begin{array}{l}2.86 \\
2.86 \\
4.76 \\
1.90 \\
0.95\end{array}$ & $\begin{array}{c}89.52 \\
92.38 \\
97.14 \\
99.05 \\
100.00\end{array}$ \\
\hline
\end{tabular}

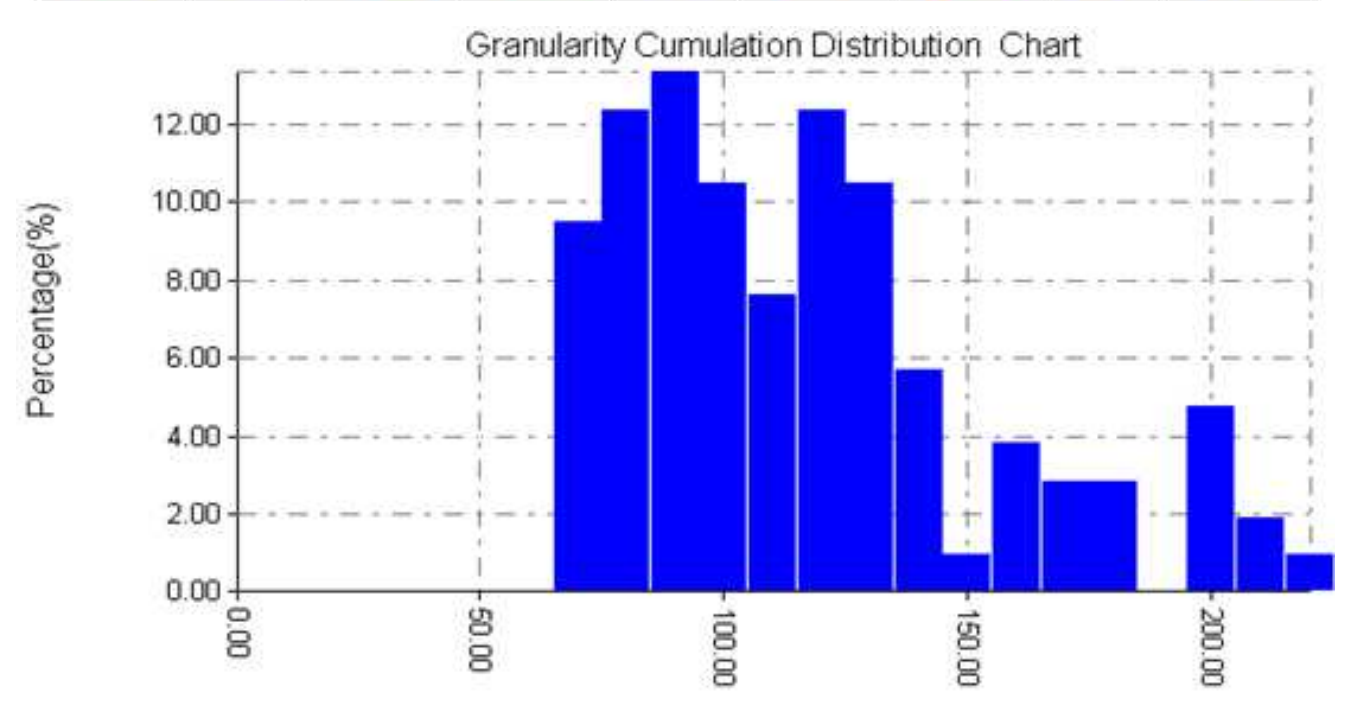

Diameter (nm)
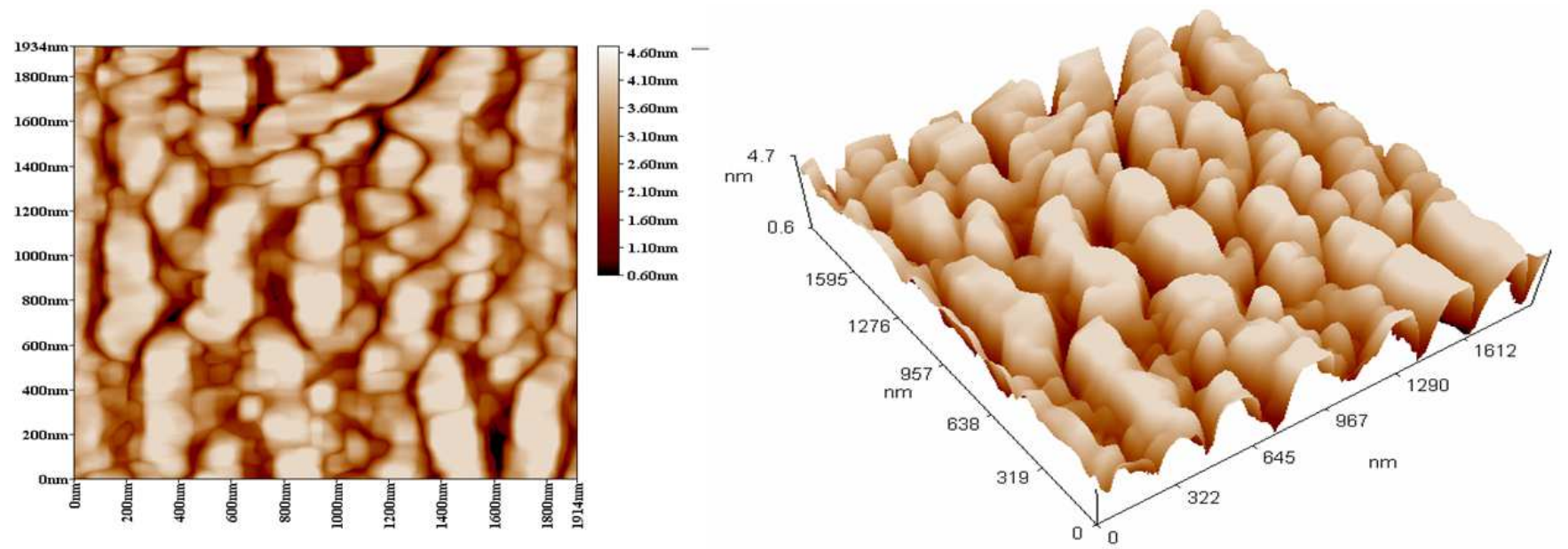

Figure (1). AFM Test of $\mathrm{ZrO}_{2}$ Particles. 


\begin{tabular}{|c|c|c|c|c|c|c|c|c|}
\hline \multicolumn{9}{|c|}{ Granularity Cumulation Distribution Report } \\
\hline \multicolumn{4}{|c|}{ Sample: HA } & \multicolumn{5}{|c|}{ Code: Sample Code } \\
\hline \multicolumn{4}{|c|}{ Line No.: lineno } & \multicolumn{5}{|c|}{ Grain No.: 198} \\
\hline \multicolumn{4}{|c|}{ Instrument: CSPM } & \multicolumn{4}{|c|}{ Date: $2013-02-09$} & \\
\hline \multicolumn{9}{|c|}{ Avg. Diameter: $69.97 \mathrm{~nm}$} \\
\hline $\begin{array}{l}\text { Diameter( } \\
\text { nm) }\end{array}$ & $\begin{array}{c}\text { Volume } \\
(\%)\end{array}$ & $\begin{array}{c}\text { Cumulatio } \\
\mathrm{n}(\%)\end{array}$ & $\begin{array}{c}\text { Diameter( } \\
n m)<\end{array}$ & $\underset{(\%)}{\text { Volume }}$ & $\underset{\mathrm{n}(\%)}{\text { Cumulatio }}$ & 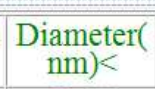 & $\begin{array}{c}\text { Volume } \\
(\%)\end{array}$ & $\begin{array}{c}\text { Cumulatic } \\
\mathrm{n}(\%)\end{array}$ \\
\hline $\begin{array}{l}20.00 \\
25.00 \\
30.00 \\
35.00 \\
40.00 \\
45.00 \\
50.00\end{array}$ & \begin{tabular}{|l|}
1.01 \\
1.01 \\
2.02 \\
5.56 \\
4.04 \\
3.54 \\
8.59
\end{tabular} & $\begin{array}{c}1.01 \\
2.02 \\
4.04 \\
9.60 \\
13.64 \\
17.17 \\
25.76\end{array}$ & $\begin{array}{l}55.00 \\
60.00 \\
65.00 \\
70.00 \\
75.00 \\
80.00 \\
85.00\end{array}$ & \begin{tabular}{|l|}
4.04 \\
5.05 \\
7.07 \\
5.56 \\
8.59 \\
7.07 \\
6.57 \\
\end{tabular} & \begin{tabular}{|l|}
29.80 \\
34.85 \\
41.92 \\
47.47 \\
56.06 \\
63.13 \\
69.70 \\
\end{tabular} & $\begin{array}{l}90.00 \\
95.00 \\
100.00 \\
105.00 \\
110.00 \\
115.00\end{array}$ & $\begin{array}{l}7.58 \\
3.54 \\
6.06 \\
6.57 \\
6.06 \\
0.51\end{array}$ & $\begin{array}{l}77.27 \\
80.81 \\
86.87 \\
93.43 \\
99.49 \\
100.00\end{array}$ \\
\hline
\end{tabular}
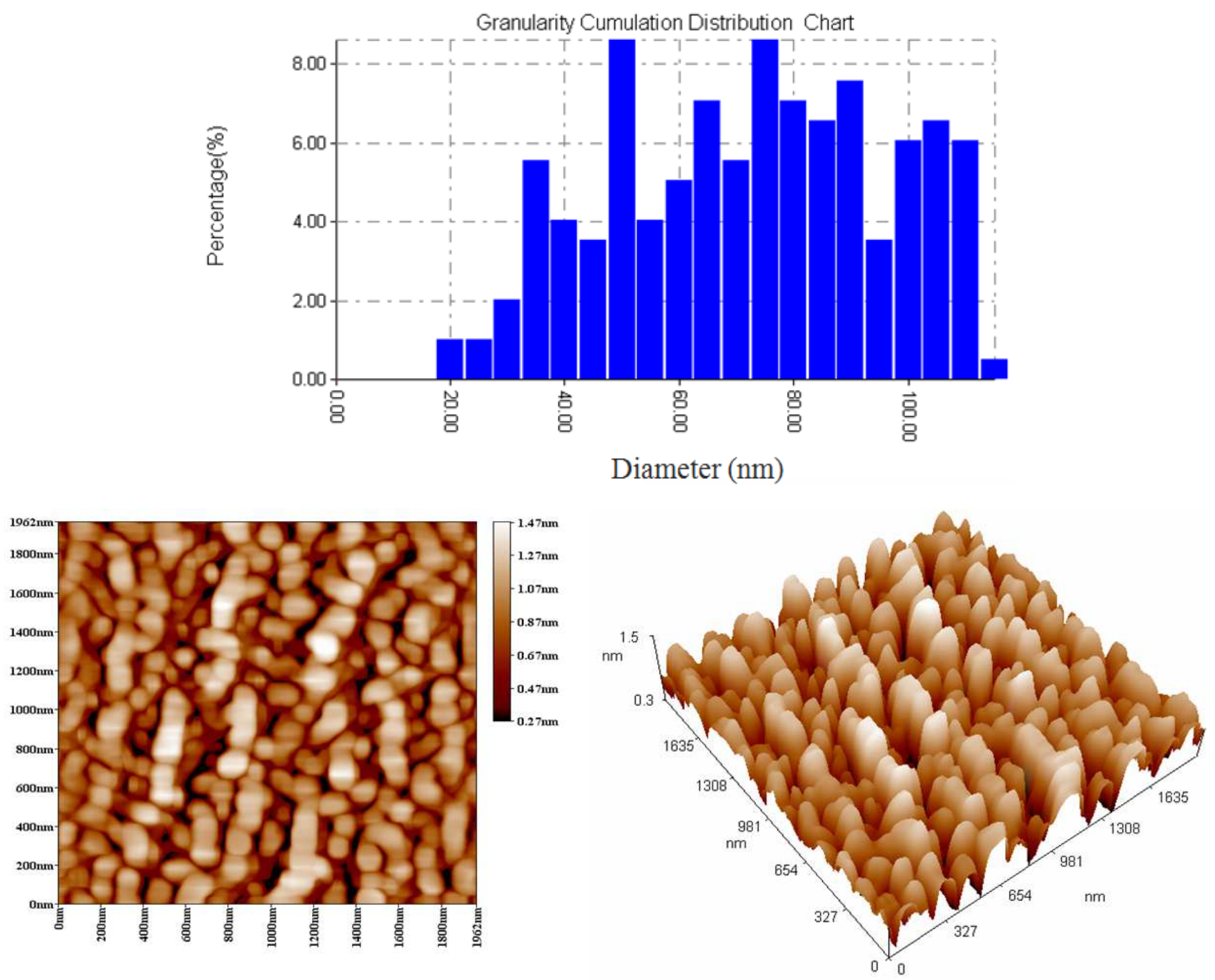

Figure (2). AFM Test of HA Particles. 


\subsection{Preparation Methods of Test Specimens}

The Vertex ${ }^{\mathrm{TM}}$ Castavaria is used to prepare the specimens of the PMMA composite materials. The proportion standard in mixing ratio is usually for cold cure acrylic resin of $17 \mathrm{~g}$ polymer powder (PMMA) and 10ml monomer liquid (MMA) $(1.7 \mathrm{~g} / 1 \mathrm{ml})$ by volume or $(1.7 \mathrm{~g}: 0.95 \mathrm{~g})$ by weight according to the manufacturer's instructions of manufacturer company. The importance of this ratio was related to control the workability of the mixture, dimensional changes on setting and considered one of the variables influence the cytotoxicity of acrylic resin [8].

When mixing powder and liquid many changes will take place due to the solution of polymer in the monomer. The stages in mixing monomer and polymer acrylic materials include (sandy or granular, sticky, full dough, rubbery and hard). The speed with which the polymer and monomer mixture reaches to dough stage depends upon the solubility of the polymer powder in the monomer liquid and increasing the temperature [9].

A mounts of the matrix and reinforced materials (particles and fibers) were calculated according to the following equation: [10].

$$
\emptyset=\frac{1}{1+\frac{1-\psi}{\psi} \times \frac{\rho_{f}}{\rho_{m}}}
$$

Where:

$\psi$ : Volume Fraction of Reinforced Materials.

$\emptyset$ : Weight Fraction of Reinforced Materials.

$\rho_{f}$ : Reinforced Materials Density $\left(\mathrm{gm} / \mathrm{cm}^{3}\right)$.

$\rho_{m}$ : Matrix Density $\left(\mathrm{gm} / \mathrm{cm}^{3}\right)$.

The Vertex Castavaria is modelable for a long period of time, where the mixture was mixed of liquid (MMA) in the clean and dry container, follow after that by slow addition of dry powder (PMMA) to liquid (MMA), the mixture stirred for $(20 \mathrm{Sec})$ until reached to the dough stage and poured with thin straight line in the center of opening mould with maximum time about (4.5 $\mathrm{min}$ ) according to manufacture company, during mixture pouring in the glass mould must be rock the mould very gently and vibrated from side to side to remove any gas bubbles from the specimens, and the reminder of the mixture was poured into mould hole until the glass mould filling. This mixture was covered in closed container and left to stand on the bench top at room temperature $\left(23 \pm 2{ }^{\circ} \mathrm{C}\right)$ for (8-13) min from beginning of mixing process as working time to increasing the viscosity of mixture and surface of the pouring has become hard and matt.

\subsection{Curing Cycle and Cooling Process}

According to the manufacture's instruction polymerization curing the closed mould was placed in the pressure vessels (autoclave). Therefore all specimens were then placed inside autoclave at $\left(55^{\circ} \mathrm{C}\right)$ and pressure equal to $(2.5$ bar $)$ and let for (30 min) according to manufacturer's instructions of manufacturer company, because of the specimens' complete polymerization under this condition. The advantage of this technique is polymerization may be accomplished in short time, post cured of specimens and give minimum level of residual monomer [11].

After complete cooling, finishing and polished of the specimen, all the tested specimens shall be stored in distilled water at $\left(37 \pm 1^{\circ} \mathrm{C}\right)$ for $(48 \mathrm{hr})$ immediately before performance any testing according to (ADA specification No.12, 1991) In order to remove any residual monomer, as well as to release residual stress and ensure remain the denture in humidity (moisture) medium [12].

\section{Mechanical Testing}

To evaluation of the compression and fatigue properties of the PMMA composite materials and hybrid laminated composite materials of the denture prosthetic, compression test and fatigue test were performed in this research. Study of this type properties for engineering material is very important because this is properties determines behaviors of these materials under different stress and condition, and can be determining the range of usefulness of a material establish the service life that can be expected for suite application. Also used to help classify and identify material. The mechanical properties of any engineering material are not constants and often change as a function of temperature, rate of loading, and other conditions [13].

\subsection{Compression Test}

The poly methyl methacrylate has adequate tensile and compressive strength for complete or partial denture applications [14].

Compressive strength is the stress required to rupture a specimen under compression load. Compression failure in composite material depended on the properties of matrix and reinforced materials such as volume fraction, interface, shape and the size of reinforced materials [15].

The compression test is performed according to (ASTM D695) by used universal testing machine (model WDW $200 \mathrm{E}$ ) made in china, at across head (strain rate) of $(5 \mathrm{~mm} / \mathrm{min})$ and load was applied until break the specimen occur. As recommended by (ADA Specification No.12, 1999), the test specimens after complete finishing and polishing processes must be stored in distilled water at $(37 \pm 1)^{\circ} \mathrm{C}$ for $(48 \mathrm{hr})$. And for this test were carried out in air at room temperature $(23 \pm 2)^{\circ} \mathrm{C}$ five specimens where used for most tests and final results represent the average for five specimens it was tested [16 and 17].

\subsection{Fatigue Test for Modified Composites}

Fatigue testing is performed by subjecting a specimen to alternating stress applications, below the yield stress until fracture occurs. This test used the specimens dimensions ( $\mathrm{L}=100 \mathrm{~mm}, \mathrm{~b}=10 \mathrm{~mm}, \mathrm{~d}=4 \mathrm{~mm}$ ), is performed according to apparatus (machine's manual) and according to (ADA Specification No.12, 1999) at room temperature. They were undertaken by the use an alternating bending fatigue testing machine with the specification of (fatigue testing machine HSM20, HI-TECH Scientific, $1400 \mathrm{rpm}$, spanning voltage $230 \mathrm{~V}$, frequency $20 \mathrm{~Hz}$, normal power $0.4 \mathrm{kw}$ ), and performed 
at stress ratio of $(\mathrm{R}=-1)$ (tension-compression) [16 and 18].

Any fracture that exacerbates deformation of the base, and later the stress distribution will predispose the denture to fracture. The midline fracture in a denture is often a result of flexural fatigue; therefore, the increased notch was a prim contributing factor in midline fracture [19]. Many factor affected on the fatigue properties and fatigue failure of composite materials include stress concentration, residual stress, micro structure of material, the interaction between the mechanical properties of the matrix and reinforcement, the strength of the bond between them, the volume fractions of constituents, the direction and type of loading, the loading frequency and temperature [20].

Fatigue damage can take the form of any, or all, of the following: delaminating, matrix cracking, fiber failure, matrix crazing, fiber /matrix deboning and void growth forming a discrete but complex damage zone. This is dependent upon variables associated with the testing conditions and the construction and composition of material [21]. The variables (elementary bending stress) can be estimated using the following equation:

$$
\sigma=\frac{M \cdot y}{I}=\frac{6 P \cdot L_{O}}{b d^{2}}
$$

Where:

$M$ : Bending Moment (N.mm).

$y$ : Position of Neutral Axis (mm).

$I$ : Moment of Inertia (mm4).

$P$ : Applied Load (N).

Lo: Original Length of the Specimen ( $\mathrm{mm})$.

$b$ : Width of the Specimen (mm).

$d$ : Thickness of the Specimen ( $\mathrm{mm}$ ).

The relationship between stress and number of cycles can be expressed in the following equation [22]:

$$
\sigma=a N^{b}
$$

Where:

$\sigma$ : Stress Applied in (MPa).

$N$ : No. of Cycle to Failure.

a \& b: Constants determined from curve fitting equation.

An effective endurance limit for steel, aluminum and titanium materials is sometimes defined as the stress that causes failure at $1 \times 10^{8}$ loading cycles and $1 \times 10^{6}$ loading cycles for polymer composite materials. The concept of an endurance limit is used in infinite-life or safe stress designs [23]. Ten points where used for each S-N curve in all cases and each point in the S-N curve represent the average of three specimens it was tested.

\section{Results and Discussion}

\subsection{Results and Discussion of the Compression Test for Modified Composites}

The compression behavior for composite prosthetic dentures represented the important mechanical properties specialization when using the polymer matrix material. The compression strength values results obtained from compression test that carried out on PMMA composite materials and hybrid laminated composite materials for all groups specimens are discussed in Figures (3), (4) and (5).

From the Figure (3) can be noticed that the values of compression strength increased with increasing the volume fraction of both types of particles for both groups of PMMA composite materials. This is due to the strengthening mechanism and the nature of bonding. Also can be related to the compressive strength of $\mathrm{HA}$ particles and the compressive strength of $\mathrm{ZrO}_{2}$ particles which are much higher than PMMA resin. Also can be noticed in this Figure, that the values of compression strength for second group ( $\mathrm{ZrO}_{2}$-PMMA) composite specimens, are higher than the values of compressive strength, for first group (nano-HA -PMMA) composite specimens. This is due to the improvement of the mechanical properties, that is associated with the addition of $\mathrm{ZrO}_{2}$ particles, which is related to the nature of $\mathrm{ZrO}_{2}$ particles which are have high compression strength, comparing with HA particles as seen from tables (1) and (2). Thus the compression strength values increased from (92.7MPa) for PMMA (as referenced) to (142.6MPa) for (PMMA-3\% $\mathrm{ZrO}_{2}$ ) composite.

From the Figures (4) and (5) can be seen that, when addition of woven mat of glass fiber or Kevlar fiber in PMMA composite, the compression strength increasing. This could be attributed to the fact that glass fibers and Kevlar fibers are characterized by their higher compressive strength than PMMA matrix, therefore that lead to improving the compressive strength of the hybrid laminated composite specimens.

And can be shown in these figures that the values of compression strength increases with increasing the volume fraction of nano-HA and $\mathrm{ZrO}_{2}$ particles with symmetrically manner approximately for all hybrid laminated composite specimens. Also can be notice from the Figures (4) and (5) that the values of compression strength for the hybrid laminated composite specimens reinforced by woven mat glass fiber are higher than values of compression strength for the hybrid laminated composite specimens reinforced by woven mat Kevlar fiber with every increase in the volume fraction of nano-HA or $\mathrm{ZrO}_{2}$ particles respectively. This is due to the characteristic that distinguished the glass fibers which have high compression strength compared with Kevlar fibers additionally to weakness the Kevlar fibers toward the axial compression load because of it have anisotropic properties [24].

As well as can be shown in these figures that the values of compression strength increased when added $\mathrm{ZrO}_{2}$ particles of the hybrid laminated composite specimens more than the values of compression strength when added nano-HA particles of the hybrid laminated specimens. This is due to the improvement of the mechanical properties that is association with the addition of $\mathrm{ZrO}_{2}$ particles to hybrid laminated composite specimens. Thus the higher values of compression strength reach to $(1114.5 \mathrm{MPa})$ for hybrid laminated composite (PMMA-5\% Glass fiber-3\% $\mathrm{ZrO}_{2}$ ). 


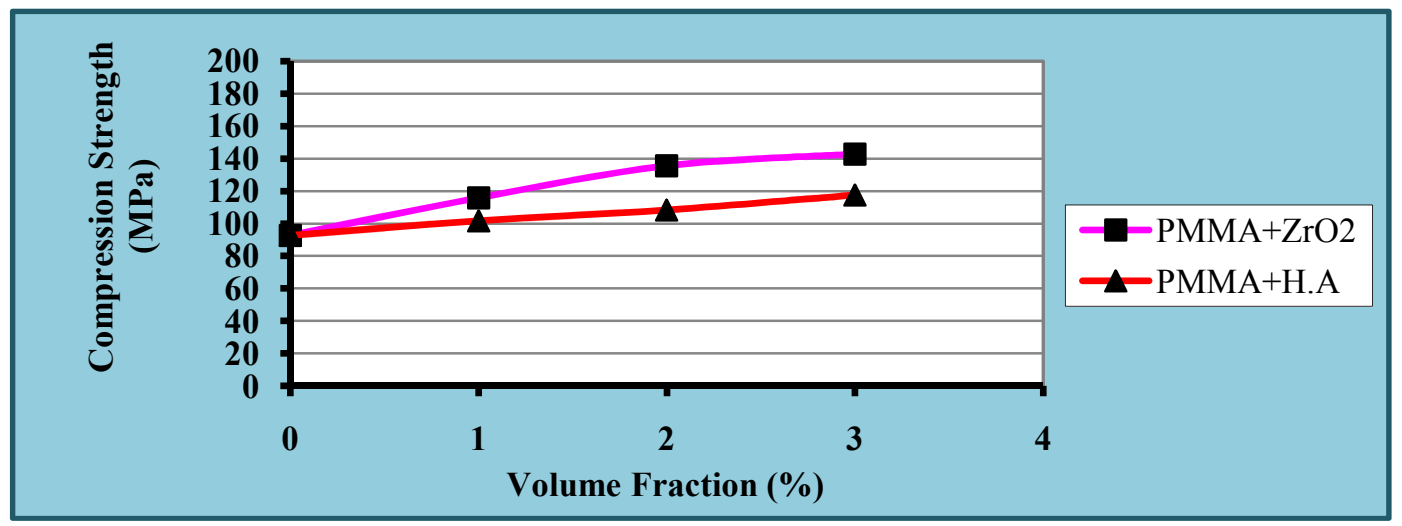

Figure (3). Compression Strength of PMMA Composite Materials as Function of (H.A or $\mathrm{ZrO}_{2}$ ) Particles (Vol \%) in Composite.

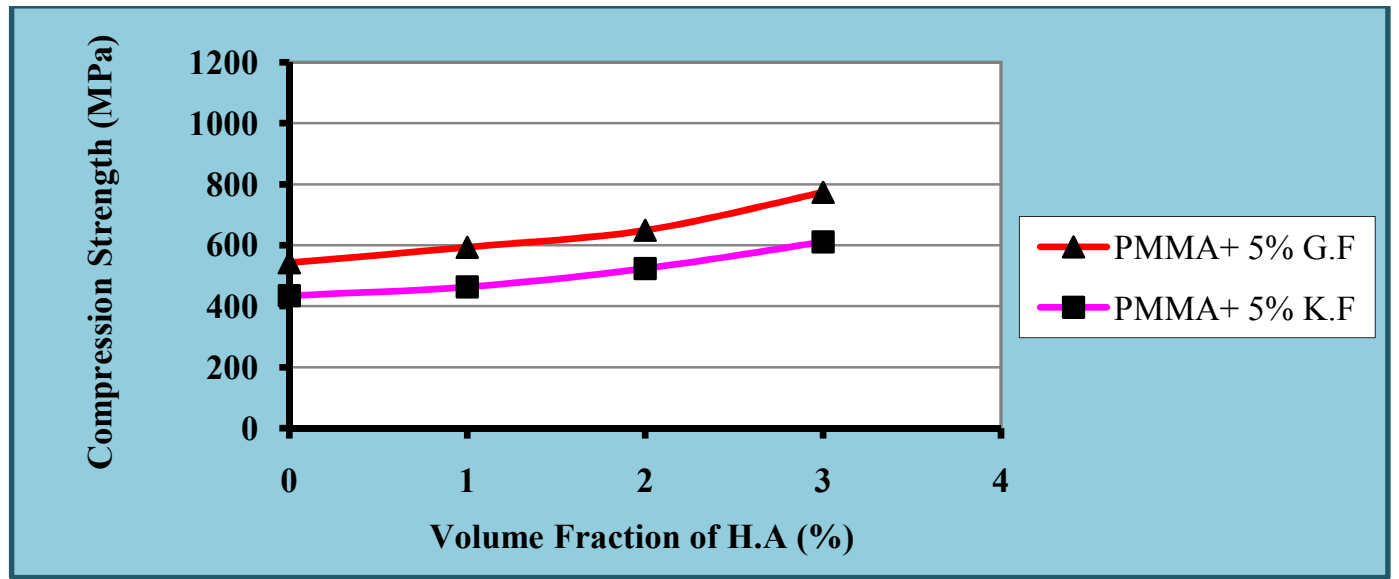

Figure (4). Compression Strength of Hybrid Laminated Composite Materials as Function of H.A Particles (Vol \%) in Composite and Type of Woven Fibers.

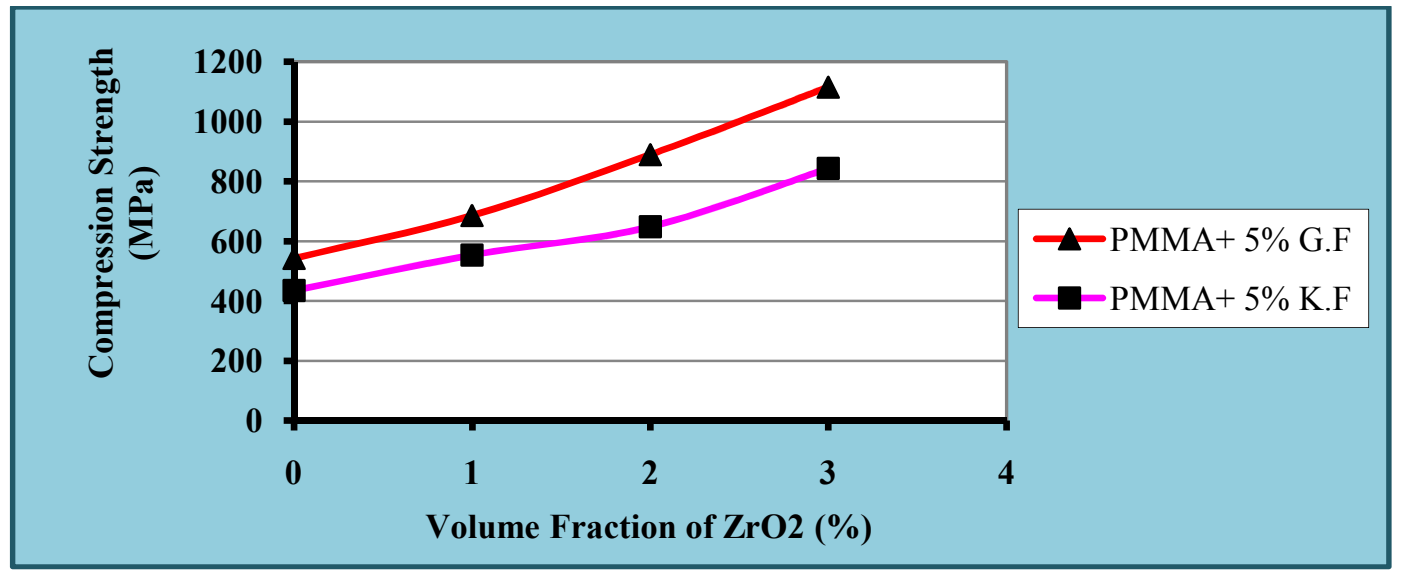

Figure (5). Compression Strength of Hybrid Laminated Composite Materials as Function of $\mathrm{ZrO}_{2}$ Particles (Vol \%) in Composite and Type of Woven Fibers.

\subsection{Results and Discussion of the Fatigue Test}

The results obtained from fatigue test that carried out on PMMA matrix and two groups of laminated composite specimens are plot of as S-N curves that shown in Figure (6). These curves are obtained by curve fitting the experimental data of fatigue test, using power formula [22].

The power equations which express the fatigue behavior of the laminated composite materials and its relative correlation coefficient $\left(\mathrm{R}^{2}\right)$ are given in this figure. It is noticed that these equations have relatively high correlation coefficient which indicate that the experimental data are well explained by power formula, since the correlation coefficient is a handy measure of the goodness of fit [25].

The fatigue stress of the tested polymer materials is taken at No. of loading Cycle of $\left(10^{6}\right)$. Since, beyond that No. of loading Cycles fatigue life becomes infinite. In general, the fatigue stress (fatigue limit) of materials is proportional to its tensile strength; hence materials with higher tensile strength possess higher fatigue stress [26 and 27].

From the Figure (6) which represents the relationship between the fatigue stress and number of loading cycles for 
[Pure PMMA, (PMMA-5\% Glass fibers-3\% nano-HA) and (PMMA-5\% Kevlar fibers-3\% nano-HA)] specimens. It can be noticed that when addition of woven mat of glass fiber or Kevlar fiber in PMMA composite, the fatigue stress increasing.

Also can be seen in this figure that the maximum value of fatigue stress was in hybrid laminated composite specimen (PMMA-5\% Kevlar fiber-3\% nano-HA), which equal to $(52 \mathrm{MPa})$ at $\left(10^{6}\right)$ loading Cycle as compared with (Pure
PMMA) which have (15MPa) and (PMMA-5\% Glass fibers-3\% nano-HA) which have (38MPa). And it was higher than the values of fatigue stress as compared with the other specimens. This is due to the high tensile strength and high modulus of elasticity that distinguished Kevlar fibers as well as high bond strength between the matrix and fibers, which lead to the preventing and hindering of crack initiation and propagation under fatigue load in fatigue stress.

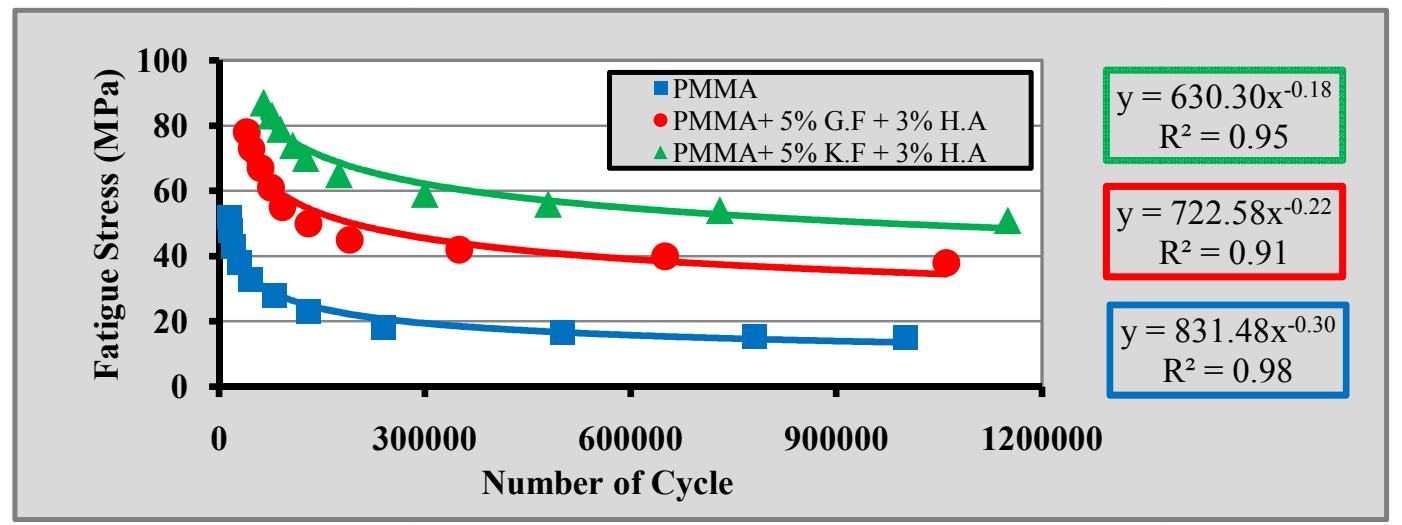

Figure (6). (S- N) Curves of PMMA Matrix and Laminated Composite Specimens Reinforcing with Glass Fibers, Kevlar Fibers and HA Particles.

\section{Conclusions}

From the presented results, can be conclusions the following:

1. The compression strength increased with increasing the volume fractions of nano-hydroxyapatite particles and micro-zirconia particles in PMMA for all types of PMMA composite.

2. The compression strength of PMMA composites (PMMA- $\mathrm{ZrO}_{2}$ ) was higher values as compared to the PMMA composites (PMMA-H.A). The compression strength values increased from $(92.7 \mathrm{MPa})$ for PMMA (as referenced) to $(142.6 \mathrm{MPa})$ for $\left(\mathrm{PMMA}-3 \% \mathrm{ZrO}_{2}\right)$ composites.

3. The addition of ( $5 \%$ glass fibers) or ( $5 \%$ Kevlar fibers) to the base PMMA as well as to the (PMMA- nano-HA) and (PMMA-Z $\mathrm{PrO}_{2}$ ) increased the compression strength for all four groups specimens of hybrid laminated composites. The higher values of compression strength reach to (1114.5MPa) for (PMMA-5\%Glass fiber-3\% $\mathrm{ZrO}_{2}$ ) composite.

4. The compression strength was higher values for hybrid laminated composites reinforced with glass fiber as compared to the compression strength of hybrid laminated composites reinforced with Kevlar fiber.

5. Fatigue strength value of hybrid laminated composite specimen (PMMA-5\% Kevlar fiber-3\%Nano-H.A), it was higher than the fatigue strength value of hybrid laminated composite specimen (PMMA-5\% Glass fiber-3\%Nano-H.A) and the Pure PMMA (as referenced) materials. The fatigue strength values at $\left(10^{6}\right)$ loading Cycle for above specimens were (52, 38 and $15 \mathrm{MPa})$ respectively.

\section{References}

[1] M. W Gaylokd; "Reinforced Plastic Theory and Practice", chners publishing co, 1974.

[2] Schajpal, S. B. and Sood, V. K., "Effect of Metal Fillers on Some Physical Properties of Acrylic Resins", Jour. Pros. Dent.; Vol. (61), PP. (746-751), (1989).

[3] Wiskott H. W. and Belser U. S., "Lack of Integration of Smooth Titanium Surface A working Hypothesis Based on Strains Generated in the Surrounding Bone ", Clin. Oral Implant Res. Journal, Vol. (10), PP. (429-444), (1999).

[4] Fujii K., "Fatigue Properties of Acrylic Denture Base Resins", Jour. Dent. Mat., Vol. (8), PP. (243-259), (1989).

[5] P. K. Vallittu."Comparison of the In vitro Fatigue Resistance with Continuous Glass Fiber or Metal Wire", Pros. Dent. Journal, Vol. (5), PP. (115-121), (1996).

[6] Cristina Bortun., "Durability Experimental Tests for A super Acrylic Plus Complete Denture", Journal T. M., Vol. (60), No. (4), PP. (269-273), (2010).

[7] William. J \& O' Brain, "Dental Materials and Their Selection", $3^{\text {rd }}$ ed., School of Dentistry, University of Michigan, (2002).

[8] Jorge. J. H, Giampaolo. E. T, Machado. A. L. and Vergani. C. E., "Cytotoxicity of Denture Base Acrylic Resins: A Literature Reviews", Journal Prosthetic Dentistry, Vol. (90), No. (2), PP. (190-193), (2003).

[9] Harrison. Z, Johnson. A, Douglas. C. W. I., "An in Vitro Study into the Effect of a limited Range of Denture Cleansers on Surface Roughness and Removal of Candida Albicans from Conventional Heat Cured Acrylic Resin Denture Base Materials", Jour. Oral Rehabil., Vol. (31), PP. (460-467), (2004). 
[10] S. I. Salih, K. M. Shabeeb \& Q. A. Hamad, "Studying Mechanical Properties for Polymer Matrix Composite Material Reinforced by Fibers and Particles", Journal of Technology University, Vol. (28), No. (4), PP (81-93) (2010).

[11] Craig. R. G. and Powers. J. M., "Restorative Dental Materials", $11^{\text {th }}$ ed., Mosby. Co., St. Louis. Missouri., USA, (2002).

[12] Ozen. A. Ugurural, Mehmet Dalkiz, and Bedri Beydemir, "The Effect of Impregnation Methods on the Cytotoxicity of A glass and Carbon Fiber-Reinforced Acrylic Resin Denture Base Materials on Oral Epithelial Cells and Fibroblasts", Journal Prosthetic Dentistry, Vol. (33), No. (9), PP. (666-673), (September, 2006).

[13] Askel and D.R. \& Phule P.P., "The Science \& Engineering of Materials", $4^{\text {th }}$ Edition Thomson Brook. Cole, 2003.

[14] Craig. R. G. and Powers. J. M., "Restorative Dental Materials", $11^{\text {th }}$ ed., Mosby. Co., St. Louis. Missouri., USA, (2002).

[15] Feih, S, Mouritz, A, Mathys, Z and Gibson., "Tensile Strength Modeling of Glass Fiber-Polymer Composites in Fire", Composite. Materials. Journal, Vol. (41), No. (19), PP. (2387-2410), (2007).

[16] Annual Book of ANSI/ADA Standard, "American National Standard/American Dental Association for Denture Base Polymers", Specification No. (12), PP. (1-14), (April, 1999).

[17] Annual Book of ASTM Standard, "Standard Test Method for Compressive Properties of Rigid Plastics", D 695-02a, PP. (1-8), (2002).

[18] Alternating Bending Fatigue Machine Instruction Manual HSM20.
[19] Jagger D. C. and Harrison, A. "The Fracture Denture-Solving the Problem", Primary Dental Care. Journal, Vol. (5), PP. (159), (1998).

[20] W. Bolten, "Engineering Materials Technology", $3^{\text {rd }}$ ed., Butterworth \& Heinemann publishing, Ltd., (1998).

[21] P. T. Curtis and A. J. Davies, "Fatigue Life Prediction of Polymer Composite Materials", Plenary lectures at ECCM9, Brighto June, (2000).

[22] Oldapo A. Aknyede, Ram Mohan, Ajit Kelkar and Jagannathan Sankar, "Static and Dynamic Loading Behavior of Hybrid Epoxy Composite with Alumina Nanoparticles", $16^{\text {th }}$ International Conference on Composite Materials, (2010).

[23] Internet,http://www.ux.uis.no/ hirpa/KdB/ME/S-N diagram.pdf, (2010).

[24] WWW. SP System.com., "SP System Guide to Composite Engineering Materials", (2004).

[25] Internet,http://pages.stern.nyu.edu/ churvich/MBA/Handouts/ 19 eg4.pdf Simple linear regression IV, "The Coefficient of Determination, $R^{2 \prime \prime},(2010)$.

[26] P. K. Mallick., "Fiber Reinforced Composites Materials, Manufacturing, and Design", $3^{\text {rd }}$ ed., Taylor \& Francis Group, LLC, (2008).

[27] B. R. Varadharajan, W. N. P. Hung and H. J. Sue., "Fatigue of Epoxy A-Zirconium Phosphate Nanocomposites", Proceedings of the ASEE Gulph-Southwest Annual Conference Texas A\&M University-Corpus Christi, (2005). 